\title{
JNPH
}

Volume 6 No. 1 (April 2018)

(C) The Author(s) 2018

\section{FAKTOR-FAKTOR KEJADIAN KARIES GIGI PADA BALITA DI WILAYAH KERJA PUSKESMAS BETUNGAN KOTA BENGKULU}

\author{
ASSOCIATED FACTORS DENTAL CARIES CASES ON TODDLERS \\ IN BETUNGAN HEALTH CENTER NURSING IN BENGKULU CITY
}

\author{
KATLI \\ UPTD PUSKESMAS PERAWATAN BETUNGAN KOTA BENGKULU \\ JLN. DEPATI PAYUNG NEGARA KM 16,5 KELURAHAN BETUNGAN KECAMATAN \\ SELEBAR KOTA BENGKULU. 38214 \\ Email: katliismail71@gmail.com/085268598590
}

\begin{abstract}
ABSTRAK
Masalah utama kesehatan mulut anak adalah karies gigi. Karies merupakan insiden masalah kesehatan gigi yang semakin meningkat. Faktor-faktor yang menyebabkan karies gigi antara lain jenis kelamin, konsumsi makanan kariogenik / manis, menyikat gigi, dokter perawatan gigi. Penelitian ini dilakukan untuk mengetahui faktor-faktor yang berhubungan dengan kejadian karies gigi pada balita di wilayah Puskesmas Betungan Kota Bengkulu. Penelitian ini merupakan penelitian analitik menggunakan desain case control. Populasi penelitian adalah semua balita yang datang mengunjungi pusat kesehatan untuk perawatan gigi, dengan ukuran sampel 96 orang, dan teknik pengambilan sampel menggunakan accidental sampling. Pengumpulan data dilakukan dengan wawancara langsung menggunakan kuesioner. Data dianalisis menggunakan analisis univariat dan bivariat dengan uji chi-square pada $\alpha 5 \%$. Hasil penelitian menunjukkan bahwa sebagian besar responden $(51,0 \%)$ sering mengonsumsi makanan kariogenik, sebagian besar responden (55,2\%) tidak menyikat gigi dengan baik, sebagian besar responden $(58,3 \%)$ melakukan perawatan gigi ke dokter tidak efektif, hampir separuh responden $(47,9 \%) . \%)$ adalah jenis kelamin perempuan, dan setengah dari responden $(50,0 \%)$ mengalami karies gigi. Ada hubungan antara konsumsi makanan kariogenik, menyikat gigi dan perawatan gigi ke dokter dengan kejadian karies gigi di Puskesma Betungan Bengkulu $(\rho=0,000)$, dan tidak ada hubungan antara jenis kelamin dan kejadian karies gigi di Puskesma Betungan Bengkulu $(\rho=0,540)$. Diharapkan bahwa petugas kesehatan di Puskesma Betungan Bengkulu menjadi saluran informasi dan memberikan konseling yang lebih intensif dan promosi kesehatan dari faktor-faktor yang terkait dengan kejadian karies gigi, serta menyampaikan pencegahan karies gigi.

Kata Kunci: Konsumsi Makanan Kariogenik, Menyikat Gigi, Perawatan Gigi ke Dokter, Karies Gigi
\end{abstract}

\begin{abstract}
The main problem of oral health of children is dental caries. Caries is a dental health problem incidence which is increasing. Factors that cause dental caries among gender, consumption of cariogenic foods/sweet, brushing teeth, dental care doctor. This study was conducted to determine the factors associated with the incidence of dental caries on toddlers in the region of
\end{abstract}


Betunganhealth center. This study was an analytical study using case control design. The study population were all toddlers who came to visit the health center for dental treatment, with the sample size of 96 people, and the sampling technique used an accidental sampling. Data collection was done by direct interview using a questionnaire. Data was analyzed using univariate and bivariate analysis with chi-square test at $\alpha 5 \%$. The results showed that most respondents $(51.0 \%)$ frequently consume cariogenic foods, most respondents $(55.2 \%)$ did not brush their teeth well, most respondents $(58.3 \%)$ carried out dental care to the doctor was not effective, almost half respondents $(47.9 \%)$ were female sex, and half of the respondents $(50.0 \%)$ experienced dental caries. There was a relationship between the consumption of foods cariogenic, brushing and dental care to the doctor with the incidence of dental caries in BetunganHealth Center in Bengkulu $(\rho=0.000)$, and there was no relationship between gender and the incidence of dental caries in Betunganhealth center in the city of Bengkulu $(\rho=0.540)$. It is expected that health workers in the health center of Betungan can be a channel of information and give more intensive counseling and health promotion of the factors associated with the incidence of dental caries, as well as convey the prevention of dental caries.

Keywords : Food Consumption Cariogenic, Brushing Teeth, Dental Care to doctor, Dental Caries

\section{PENDAHULUAN}

Karies gigi sejauh ini masih menjadi masalah kesehatan anak. Organisasi Kesehatan Dunia (WHO) tahun 2016 menyatakan angka kejadian karies pada anak masih sebesar 60-90\%. Menurut hasil penelitian di negara - negara Eropa, Amerika dan Asia termasuk Indonesia, ternyata bahwa $90-100 \%$ anak di bawah 18 tahun terserang karies gigi.

Menurut Riskesda 2017 di Indonesia terjadi peningkatan prevalensi terjadinya karies aktif pada penduduk Indonesia dibandingkan tahun 2010 lalu, yaitu dari 43,4 $\%$ (2007) menjadi 53,2 \% atau 93 juta jiwa (2013).

Faktor yang menyebabkan terjadinya karies gigi antara lain adalah faktor keturunan, ras, jenis kelamin, umur, jenis makanan, frekuensi menyikat gigi yang benar, kebiasaan jelek dan pentingnya kontrol ke dokter, faktor host yaitu kekuatan dari permukaan gigi, adanya plak yang berisi bakteri, biasanya bakteri patogen yang kariogenik seperti Streptococcus mutans (Tarigan, 2012).

Apabila karies gigi ini dibiarkan tanpa diatasi maka akan terjadi beberapa komplikasi seperti timbulnya peradangan dan nanah pada gusi, abses pada jaringan gusi dan otot, peradangan pada tulang rahang bahkan kematian pada tulang rahang, Sellulitis, pembengkakan dan peradangan di kerongkongan sehingga menyebabkan kesulitan menelan dan tidak bisa membuka mulut, bahkan dapat menyebabkan jantung (Ramadhan, 2010).

Menurut data Puskesmas Betungan jumlah kejadian karies gigi pada balita bulan Januari-September 2016 berjumlah 91 orang dengan laki-laki 38 orang dan 53 perempuan. Berdasarkan survey awal di Wilayah Kerja Puskesmas BetunganKota Bengkulu terhadap orang tua dan balita yang berobat ke Poli Gigi Puskesmas Betungandari 8 orang terdapat 7 orang balita yang mengalami karies gigi dan 1 orang tidak.

Berdasarkan latar belakang diatas penulis tertarik untuk melakukan penelitian tentang "faktor-faktor yang berhubungan dengan kejadian karies gigi pada balita di Wilayah Kerja Puskesmas BetunganKota Bengkulu”.

\section{BAHAN DAN METODE}

Teknik pengumpulan data yang digunakan dalam penelitian ini adalah dengan menggunakan data primer dan data sekunder. Data primer adalah data yang dikumpulkan melalui penyebaran kuesioner langsung pada 
responden di Puskesmas BetunganKota Bengkulu. Sedangkan data sekunder adalah data yang diperoleh dari laporan tahunan dinas kesehatan kota Bengkulu dan buku register poli gigi puskesmas Betungankota Bengkulu. Uji statistik menggunakan uji chisquare dengan tingkat kepercayaan $95 \% \alpha=$ 0,05

Penelitian ini menggunakan case control. Populasi pada penelitian ini adalah seluruh balita yang datang berkunjung berobat ke poli gigi Puskesmas BetunganKota Bengkulu dari bulan Januari-September 2016 sebanyak 91 orang. Teknik pengambilan sampel dengan accidental sampling,

\section{HASIL PENELITIAN}

Puskesmas Betunganterdiri dari Puskesmas Induk dan Pustu L.Butai, K.Tebeng, dan SL.Baru. Program yang dilaksanakan di Puskesmas Sawah Lebar, terdapat enam program yaitu Kesehatan Ibu dan Anak (KIA), Keluarga Berencana (KB), Kesehatan Lingkungan, Pemberantasan Penyakit Menular (P2M), promosi kesehatan, dan perbaikan gizi (Profil Puskesmas Bentungan, 2015).

Data yang diperoleh dari penelitian kemudian dikelompokan dan ditabulasi sesuai dengan keperluan peneliti. Selanjutnya peneliti melakukan pengolahan data dan analisis data. Hasil penelitian disajikan dalam analisis univariat dari setiap variable independen dan dependen. penyajian dilanjutkan dengan hasil analisis bivariat yang bertujuan untuk mengetahui hubungan antara variabel independen dengan variabel dependen. Dengan hasil penelitian sebagai berikut:

Tabel 1 Distribusi Frekuensi Umur pada Balita di wilayah kerja puskesmas Betungan kota Bengkulu

\begin{tabular}{ccc}
\hline Umur & Frekuensi & Persentase (\%) \\
\hline Toddler (1-3 tahun) & 50 & 52,1 \\
\hline $\begin{array}{c}\text { Para sekolah }(<3-5 \\
\text { tahun) }\end{array}$ & 46 & 47,9 \\
\hline
\end{tabular}

\begin{tabular}{ccc}
\hline Total & 96 & 100,0 \\
\hline
\end{tabular}

Berdasarkan tabel 1 di atas dapat diketahui bahwa sebagian besar responden $(52,1 \%)$ umur toddler.

Tabel 2 Distribusi Frekuensi Konsumsi Makanan Kariogenik pada Balita di wilayah kerja puskesmas Betungan kota Bengkulu thun 2016

\begin{tabular}{ccc}
\hline $\begin{array}{c}\text { Konsumsi Makanan } \\
\text { Kariogenik }\end{array}$ & Frekuensi & Persentase (\%) \\
\hline Sering & 49 & 51,0 \\
Jarang & 47 & 49,0 \\
\hline Total & 96 & 100,0 \\
\hline
\end{tabular}

Berdasarkan tabel 2 di atas dapat diketahui bahwa sebagian besar responden $(51,0 \%)$ sering konsumsi makanan kariogenik.

Tabel 3 Distribusi Frekuensi Menggosok Gigi pada Balita di wilayah kerja puskesmas Betungankota Bengkulu tahun 2016

\begin{tabular}{ccc}
\hline Menggosok Gigi & Frekuensi & Persentase $(\%)$ \\
\hline Tidak Baik & 53 & 55,2 \\
Baik & 43 & 44,8 \\
\hline Total & 96 & 100,0 \\
\hline
\end{tabular}

Berdasarkan tabel 3 di atas dapat diketahui bahwa sebagian besar responden $(55,2 \%)$ menggosok gigi tidak baik.

Tabel 4 Distribusi Frekuensi Perawatan Gigi ke dokter pada Balita diwilayah kerja puskesmas Betungan kota Bengkulu.

\begin{tabular}{ccc}
\hline Perawatan Gigi ke Dokter & Frekuensi & Persentase (\%) \\
\hline Tidak Efektif & 56 & 58,3 \\
Efektif & 40 & 41,7 \\
\hline Total & 96 & 100,0 \\
\hline
\end{tabular}

Berdasarkan tabel 4 di atas dapat diketahui bahwa sebagian besar responden $(58,3 \%)$ perawatan gigi ke dokter tidak efektif. 
Tabel 5 Distribusi Frekuensi Jenis Kelamin pada Balita di wilayah kerja puskesmas Betungankota Bengkulu.

\begin{tabular}{ccc}
\hline Jenis Kelamin & Frekuensi & Persentase (\%) \\
\hline Perempuan & 46 & 47,9 \\
Laki-laki & 50 & 52,1 \\
\hline Total & 96 & 100,0 \\
\hline
\end{tabular}

Berdasarkan tabel 5 di atas dapat diketahui bahwa sebagian besar responden $(52,1 \%)$ berjenis kelamin laki-laki.

Tabel 6 Distribusi Frekuensi Kejadian Karies Gigi pada Balita di wilayah kerja puskesmas Betungankota Bengkulu.

\begin{tabular}{ccc}
\hline $\begin{array}{c}\text { Kejadian Karies } \\
\text { Gigi }\end{array}$ & Frekuensi & Persentase (\%) \\
\hline Ya & 48 & 50,0 \\
Tidak & 48 & 50,0 \\
\hline Total & 96 & 100,0 \\
\hline
\end{tabular}

Berdasarkan tabel 6 di atas dapat diketahui bahwa setengah responden $(50,0 \%)$ mengalami karies gigi.

Tabel 7 Hubungan Konsumsi Makanan Kariogenik dengan Kejadian Karies Gigi pada Balita di wilayah kerja puskesmas Betungan kota Bengkulu

\begin{tabular}{|c|c|c|c|c|}
\hline \multirow{3}{*}{$\begin{array}{l}\text { Konsumsi } \\
\text { Makanan } \\
\text { Kariogenik }\end{array}$} & \multicolumn{2}{|c|}{$\begin{array}{c}\text { Kejadian Karies } \\
\text { Gigi }\end{array}$} & \multirow[t]{2}{*}{ Total } & \multirow{3}{*}{$\rho$} \\
\hline & $\mathrm{Ya}$ & Tidak & & \\
\hline & $\mathrm{n} \quad \%$ & n $\%$ & N \% & \\
\hline $\begin{array}{l}\text { Sering } \\
\text { Jarang }\end{array}$ & $\begin{array}{cc}42 & 85,7 \\
6 & 12,8\end{array}$ & $\begin{array}{cc}7 & 14,3 \\
41 & 87,2\end{array}$ & $\begin{array}{ll}49 & 100,0 \\
47 & 100,0\end{array}$ & 0,000 \\
\hline
\end{tabular}

Berdasarkan tabel 7 diatas diketahui dari 49 responden yang sering konsumsi makanan kariogenik terdapat hampir seluruh responden $(85,7 \%)$ mengalami karies gigi. Berdasarkan hasil analisis uji chi-square (Continuity Correction) didapatkan nilai $\rho=$ $0,000<\alpha 0,05$ berarti signifikan maka Ho ditolak dan $\mathrm{Ha}$ diterima, dan dapat disimpulkan bahwa ada hubungan yang bermakna antara konsumsi makanan kariogenik dengan kejadian karies gigi.

Tabel 8 Hubungan Menggosok Gigi dengan Kejadian Karies Gigi pada Balita di wilayah kerja puskesmas Betungan kota bengkulu

\begin{tabular}{|c|c|c|c|c|c|c|c|}
\hline \multirow{3}{*}{$\begin{array}{l}\text { Menggosok } \\
\text { Gigi }\end{array}$} & \multicolumn{4}{|c|}{$\begin{array}{c}\text { Kejadian Karies } \\
\text { Gigi }\end{array}$} & \multirow{2}{*}{\multicolumn{2}{|c|}{ Total }} & \multirow{3}{*}{$\mathrm{P}$} \\
\hline & \multicolumn{2}{|c|}{$\mathrm{Ya}$} & \multicolumn{2}{|c|}{ Tidak } & & & \\
\hline & $\mathrm{n}$ & $\%$ & $\mathrm{n}$ & $\%$ & $\mathrm{n}$ & $\%$ & \\
\hline Tidak Baik & 39 & 73,6 & 14 & 26,4 & & 100,0 & \\
\hline Baik & 9 & 20,9 & 34 & 79,1 & 43 & 100,0 & 0,000 \\
\hline
\end{tabular}

Berdasarkan tabel 8 diatas diketahui dari 53 responden menggosok gigi tidak baik terdapat sebagian besar responden $(73,6 \%)$ mengalami karies gigi. Berdasarkan hasil analisis uji chi-square (Continuity Correction) didapatkan nilai $\rho=0,000<\alpha 0,05$ berarti signifikan maka Ho ditolak dan Ha diterima, dan dapat disimpulkan bahwa ada hubungan yang bermakna antara menggosok gigi dengan kejadian karies gigi.

Tabel 9 Hubungan perawatan gigi kedokter dengan Kejadian Karies Gigi pada Balita Di Wilayah Kerja Puskesmas BetunganKota Bengkulu

\begin{tabular}{|c|c|c|c|c|c|c|c|}
\hline \multirow{4}{*}{$\begin{array}{l}\text { Perawatan Gigi } \\
\text { ke Dokter }\end{array}$} & \multirow{2}{*}{\multicolumn{4}{|c|}{$\begin{array}{c}\text { Kejadian Karies } \\
\text { Gigi }\end{array}$}} & \multirow{3}{*}{\multicolumn{2}{|c|}{ Total }} & \multirow{4}{*}{$\mathrm{P}$} \\
\hline & & & & & & & \\
\hline & \multicolumn{2}{|c|}{ Ya } & \multicolumn{2}{|c|}{ Tidak } & & & \\
\hline & $\mathrm{n}$ & $\%$ & $\mathrm{n}$ & $\%$ & $\mathrm{~N}$ & $\%$ & \\
\hline Tidak Efektif & 44 & 78,6 & 12 & 21,4 & 56 & 100 & \\
\hline Efektif & 4 & 10,0 & 36 & 90,0 & 40 & 100 & 0,000 \\
\hline
\end{tabular}

Berdasarkan tabel 9 diatas diketahui dari 56 responden yang perawatan gigi ke dokter tidak efektif terdapat hampir seluruh responden $(78,6 \%)$ mengalami karies gigi. Berdasarkan hasil analisis uji chi-square (Continuity Correction) didapatkan nilai $\rho=$ $0,000<\alpha 0,05$ berarti signifikan maka Ho ditolak dan $\mathrm{Ha}$ diterima, dan dapat disimpulkan bahwa ada hubungan yang bermakna antara perawatan gigi ke dokter dengan kejadian karies gigi. 
Tabel 10 Hubungan Jenis Kelamin dengan Kejadian Karies Gigi pada Balita di wilayah kerja puskesmas Betungan kota bengkulu

\begin{tabular}{cccccccc}
\hline \multirow{2}{*}{ Jenis } & \multicolumn{8}{c}{ Kejadian Karies Gigi } & \multirow{2}{*}{ Total } & \multirow{2}{*}{$\mathrm{P}$} \\
\cline { 2 - 5 } Kelamin & \multicolumn{2}{c}{ Ya } & \multicolumn{2}{c}{ Tidak } & & \\
\cline { 2 - 6 } & $\mathrm{n}$ & $\%$ & $\mathrm{n}$ & $\%$ & $\mathrm{n}$ & $\%$ & \\
\hline Perempuan & 25 & 54,3 & 21 & 45,7 & 46 & 100,0 & \multirow{2}{*}{0,540} \\
Laki-laki & 23 & 46,0 & 27 & 54,0 & 50 & 100,0 & \\
\hline
\end{tabular}

Berdasarkan tabel 10 diatas diketahui dari 50 responden berjenis kelamin laki-laki terdapat hampir sebagian responden $(46,0 \%)$ mengalami karies gigi. Berdasarkan hasil analisis uji chi-square (Continuity Correction) didapatkan nilai $\rho=0,540>\alpha 0,05$ berarti tidak signifikan maka Ha ditolak dan Ho diterima, dan dapat disimpulkan bahwa tidak ada hubungan yang bermakna antara jenis kelamin dengan kejadian karies gigi.

\section{PEMBAHASAN}

Berdasarkan hasil penelitian diketahui bahwa sebagian besar responden $(52,1 \%)$ berumur 1-3 tahun (toddler). Hal ini juga sesuai dengan teori dimana Faktor yang menyebabkan terjadinya karies gigi antara lain adalah faktor keturunan, ras, jenis kelamin, umur, jenis makanan, frekuensi menyikat gigi yang benar, kebiasaan jelek dan pentingnya kontrol ke dokter, faktor host yaitu kekuatan dari permukaan gigi, adanya plak yang berisi bakteri, biasanya bakteri patogen yang kariogenik seperti Streptococcus mutans (Tarigan, 2012). Berdasarkan hasil penelitian diketahui sebagian besar responden $(51,0 \%)$ sering konsumsi makanan kariogenik, sebagian besar responden $(55,2 \%)$ menggosok gigi tidak baik, sebagian besar responden $(58,3 \%)$ perawatan gigi ke dokter tidak efektif, sebagian besar responden $(52,1 \%)$ berjenis kelamin laki-laki, dan setengah responden $(50,0 \%)$ karies gigi. Berdasarkan hasil analisis uji chi-square (Continuity Correction) didapatkan nilai $\rho=0,000<\alpha 0,05$ berarti signifikan maka Ho ditolak dan Ha diterima, dan dapat disimpulkan bahwa ada hubungan yang bermakna antara konsumsi makanan kariogenik dengan kejadian karies gigi. Berdasarkan hasil analisis uji chi-square (Continuity Correction) didapatkan nilai $\rho=$ $0,000<\alpha 0,05$ berarti signifikan maka Ho ditolak dan $\mathrm{Ha}$ diterima, dan dapat disimpulkan bahwa ada hubungan yang bermakna antara menggosok gigi dengan kejadian karies gigi.Berdasarkan hasil analisis uji chi-square (Continuity Correction) didapatkan nilai $\rho=0,000<\alpha 0,05$ berarti signifikan maka Ho ditolak dan Ha diterima, dan dapat disimpulkan bahwa ada hubungan yang bermakna antara perawatan gigi ke dokter dengan kejadian karies gigi.Berdasarkan hasil analisis uji chi-square (Continuity Correction) didapatkan nilai $\rho=$ $0,540>\alpha 0,05$ berarti tidak signifikan maka Ha ditolak dan Ho diterima, dan dapat disimpulkan bahwa tidak ada hubungan yang bermakna antara jenis kelamin dengan kejadian karies gigi.

\section{KESIMPULAN}

Dari hasil penelitian yang telah dilakukan dapat disimpulkan sebagai berikut :

1. Sebagian besar balita di Wilayah Kerja Puskesmas Betungan Kota Bengkulu sering konsumsi makanan kariogenik.

2. Sebagian besar balita di Wilayah Kerja Puskesmas Betungan Kota Bengkulu menggosok gigi tidak baik.

3. Sebagian besar balita di Wilayah Kerja Puskesmas Betungan Kota Bengkulu perawatan gigi ke dokter tidak efektif.

4. Sebagian besar balita di Wilayah Kerja Puskesmas Betungan Kota Bengkulu berjenis kelamin laki-laki.

5. Sebagian balita di Wilayah Kerja Puskesmas Betungan Kota Bengkulu mengalami karies gigi.

6. Ada hubungan yang bermakna antara konsumsi makanan kariogenik dengan kejadian karies gigi pada balita di Wilayah Kerja Puskesmas Betungan Kota Bengkulu. 
7. Ada hubungan yang bermakna antara menggosok gigi dengan kejadian karies gigi pada balita di Wilayah Kerja Puskesmas Betungan Kota Bengkulu.

8. Ada hubungan yang bermakna antara perawatan gigi ke dokter dengan kejadian karies gigi pada balita di Wilayah Kerja Puskesmas Betungan Kota Bengkulu.

9. Tidak ada hubungan yang bermakna antara jenis kelamin dengan kejadian karies gigi pada balita di Wilayah Kerja Puskesmas Betungan Kota Bengkulu.

\section{SARAN}

Berdasarkan dari kesimpulan hasil penelitian yang telah dilakukan di Puskesmas Betungan Kota Bengkulu, maka penulis menyarankan:

\section{Akademik}

Penelitian ini diharapkan dapat menjadi sumber pengetahuan tentang faktor-faktor yang berhubungan dengan karies gigi, sehingga peneliti selanjutnya tidak mengalami kesulitan untuk mencari referensi.

\section{Peneliti Selanjutnya}

Bagi peneliti selanjutnya disarankan agar dapat menyempurnakan penelitian ini dengan metode yang lebih lengkap diantaranya pengumpulan data tidak hanya menggunakan kuesioner tetapi diikuti dengan observasi, serta wawancara yang mendalam dan menggunakan variabel lainnya sehingga didapatkan hasil yang lebih baik.

\section{Bagi Dinas Kesehatan Kota Bengkulu}

Pihak pemerintah dalam hal ini Dinas

Kesehatan perlu menyusun program kegiatan untuk memberi edukasi atau penyuluhan yang dapat membantu meningkatkan pengetahuan ibu-ibu tentang faktor-faktor yang berhubungan dengan karies gigi, dan cara pencegahan karies gigi terhadap anak mereka, sehingga dapat menurunkan angka kejadian karies gigi pada anak dan meningkatkan derajat kesehatan masyarakat.

4. Bagi Pihak Puskesmas

Disarankan agar petugas kesehatan di Puskesmas Betungandapat menjadi penyalur informasi dan lebih intensif memberikan konseling dan promosi kesehatan tentang pengaruh konsumsi makanan kariogenik, menggosok gigi dan perawatan gigi ke dokter terhadap timbulnya karies gigi, serta menyampaikan cara pencegahan timbulnya karies gigi.

\section{DAFTAR PUSTAKA}

Anggraeni. 2007. Hubungan antara Tingkat Konsumsi Karbohidrat dan Frekuensi Makan Makanan Kariogenik dengan Kejadian Penyakit Karies Gigi pada Anak Pra Sekolah di TK Aba 52

Semarang. Diakses dari http://lib.unnes.ac.id /6311/1/3831.pdf tanggal 25 November 2015.

Anggraeni. 2013. Hubungan antara Kebiasaan Mengkonsumsi Jajanan Kariogenik dan Menggosok Gigi dengan Kejadian Karies Gigi pada Anak Sekolah Kelas 1-6 di SDN 01 Watuaji Keling Jepara. Diakses dari http://download.portalgaruda. org/article.php tanggal 25 November 2015.

Arikunto. 2009. Prosedur Penelitian. Jakarta : Rineka Cipta.

Fergiliana. 2014. Faktor-faktor yang berhubungan dengan timbulnya Karies Gigi pada siswa-siswi di SD inpres Tenda-Ruteng Kabupaten Manggarai. Diakses dari https://www.google.co.id/ tanggal 15 Oktober 2015.

Ginting. 2008. Mulut sehat gigi kuat. Bandung: Indonesia Publising House.

Hariadi. 2011. Faktor-Faktor-YangMenyebabkan Karies Gigi (diakses dari http://kti-akbid.blogspot.co.id 15 Oktober).

Hermita. 2010. Hubungan Tingkat Pendidikan dan Sikap dengan Persepsi 
Ibu tentang Kejadian Karies Gigi pada Anak Pra Sekolah di Desa Sumberjo Rembang. Diakses dari http://digilib.unimus.ac.id/gdl.php tanggal 17 Oktober 2015.

Intan. 2013. Penyakit Gigi, Mulut dan THT. Yogyakarta : Nuha Medika.

Kartikasari. 2013. Hubungan Konsumsi Makanan Kariogenik dengan Kejadian Karies Gigi dan Status Gizi pada Anak Kelas III dan IV SDN Kadipaten I dan II Kabupaten Bojonegoro. Diakses dari http://eprints.undip.ac.id tanggal 17 Oktober 2015.

Khotimah. 2013. Faktor - faktor yang berhubungan dengan Kejadian Karies Gigi pada Anak Usia 6-12 Tahun di SD Negeri Karangayu 03 Semarang. Diakses darihttp://download.portalgaruda.org/ar ticle.php tanggal 20 November 2015.

Maulidta. 2010. Hubungan kebiasaan menggosok gigi dan kebiasaan mengkonsumsi jajanan kariogenik dengan kejadian karies gigi pada anak usia prasekolah di Taman Kanak Kanak Pondok Beringin Semarang. Diakses dari http://eprints.undip.ac.id/16056/ tanggal 17 Oktober 2015.

Notoatmodjo, S. 2012. Metodologi Penelitian Kesehatan. Jakarta : Rineka Cipta

Nugroho. 2015. Hubungan Pola Jajan Kariogenik dan Kebiasaan Menggosok Gigi Terhadap Kejadian Karies Gigi Molar Pertama Permanen Pada AnakUsia 8-10 Tahun di SDN 01 Gumpang Kecamatan Kartasura, Sukoharjo. Diakses dari http://eprints.ums.ac.id/.pdf tanggal 13 Februari 2016.

Profil Puskesmas Sawah Lebar. 2016. Profil Puskesmas sawah Lebar. Bengkulu: Puskesmas Kota Bengkulu.

Ramadhan, A. 2010. Serba serbi Kesehatan Gigi dan Mulut. Jakarta: Bukune.

Riskesda. 2017. 93 Juta Lebih Penduduk Indonesia Menderita Karies Aktif. Diakses http://www.kompasiana.com tanggal 12 November 2017.

Tarigan. 2012. Karies Gigi. Medan : EGC.

WHO. 2016. Kasus Karies pada Anak Balita. (diakses dari http://health.kompas.com 15 Oktober 2017 